DOI 10.17150/978-5-7253-3001-4.39

УДК 378(470+571)(091)

ББК $74.483(2 \mathrm{Poc})$

\title{
МЕЖДУ «УНИВЕРСИТЕТОМ В РУССКОМ СМЫСЛЕ» И ПОЛИТЕХНИКУМОМ: дискуссия 1912 года о желательном типе высшего учебного заведения для Иркутска
}

В центре внимания статьи находятся события осени 1912 г., связанные с участием Иркутска, наряду с другими сибирскими городами, в борьбе за право открыть у себя высшее учебное заведение - сельскохозяйственный институт. Так и не осуществленный проект Главного управления землеустройства и земледелия породил не одни только несбывшиеся ожидания. Свое значение для университетской истории сохранили разворачивавшиеся в рамках общественных организаций обсуждения вопроса о желательном для города типе высшего учебного заведения, выявившие приоритет, отдававшийся участниками школе народнохозяйственной.

Ключевые слова: университетская история, народнохозяйственная высшая школа, политехникум, университет, Иркутск.

\section{D.YA. MAIDACHEVSKY}

\section{BETWEEN «THE UNIVERSITY IN A RUSSIAN SENSE» AND THE POLYTECHNIC: \\ The discussion of 1912 on desired kind of higher education institution for Irkutsk}

The article deals with discussion of 1912, when Irkutsk competed with other cities for the right to open an agricultural institute. The unrealized project of the General Directorate of Land Management and Agriculture has not only failed with unfulfilled expectations. The significance for history has been left by the discussion about desired kind of higher education institution for the city, which revealed the priority given by public organizations to national-economy higher school.

Keywords: history of universities, national-economy higher school, polytechnic, agricultural institute, university, Irkutsk.

Автору статьи уже доводилось на страницах своих работ отмечать фракт того, что история высшей школы восточносибирского региона в целом, и Иркутска в частности, вплоть до начала 1930-х гг. была университетской историей, а непосредственно предшествовавшая открытию в 1918 г. Иркутского государственного университета - историей «университетского вопроса» [9]. Со всеми вытекающими из подобного подхода негативными последствиями для проблемной области истории высшей 
школы региона, имея в виду, прежде всего, историю школы «специальной», отдельные отрасли которой хорошо обнимаются термином «народнохозяйственной». На сей раз, однако, автор предпочел остаться в пределах университетской истории и «университетского вопроса», соответственно, хотя и выйти за давно ставшие узкими рамки рассмотрения последнего на местном материале как проблемы территориального размещения университетов на пространстве Российской империи, и конкретно - открытия последних на далекой ее сибирской окраине.

В центре внимания данной статьи находятся события осени 1912 г., связанные с участием Иркутска, наряду с семью другими сибирскими городами (Томском, Омском, Ново-Николаевском, Барнаулом, Красноярском, Семипалатинском и Нерчинском), в борьбе за право открыть у себя высшее учебное заведение - сельскохозяйственный институт. Так и не осуществленный проект Главного управления землеустройства и земледелия (разрабатывавшийся, заметим, при непосредственном участии будущего министра народного просвещения Павла Николаевича Игнатьева (1870-1945)) [8, с. 89-90] породил не одни только несбывшиеся ожидания. Свое значение для университетской истории сохранили обсуждения, проходившие в городской управе, Иркутском биржевом комитете, Обществе изучения Сибири и Восточно-Сибирском отделе Императорского русского географического общества.

Вопреки ожиданиям, оперативно публиковавшиеся на страницах иркутских газет информационные материалы, а также увидевшие вслед за ними свет стенограммы заседаний и тексты сделанных докладов и памятных записок, полны не только единодушия в вопросе о праве и возможности города принять у себя высшее учебное заведение, но и полемики о «желательном его типе». И речь шла, как бы не подводил к такому заключению породивший эту полемику повод, отнюдь не об одном только противопоставлении университета и отраслевого вуза, образования «общего» и «профессионального». Хотя среди участников было немало «прагматиков», призывавших довольствоваться «малым» учитывая как текущую политическую ситуацию в стране, так и негативное отношение «правящих сфер» к идее открытия новых университетов, обсуждение сумело подняться над суетой политических будней и затронуть вопрос о типах универсального образования. Тем более что уже проектируемый институт должен был включать агрономический, ветеринарный, культурно-технический и лесной фракультеты [8, с. 90].

Обсуждения осени 1912 г. интересны еще и потому, что нередко рассматриваются историками, игнорирующими их ход и результаты, в качестве всего лишь стартовой линии той финишной прямой, что привела осенью 1918 г. к естественному и закономерному итогу - открытию Иркутского университета [13, с. 14]. Встраиваемая в один ряд со стартовавшими в том же году сбором средств на нужды будущего университета 
Иркутским культурно-просветительским обществом и формированием его библиотеки, полемика эта заслуживает, однако, на наш взгляд, куда большего внимания. Выходя далеко за рамки этого «краеведческого» по своему характеру событийного ряда, она выводит и траекторию развития высшей школы региона на принципиально иную, более высокую орбиту университетской (кто-то скажет - контрфактической) истории страны на одном из интереснейших этапов ее развития.

Начало полемике было положено 27 октября 1912 г. на развернувшемся в ходе общего собрания Восточно-Сибирского отдела Императорского русского географического общества (ВСОИРГО) обсуждении доклада правителя дел последнего Федора Геннадьевича Ширяева (1868-1920). Примечательно, что исполнительный орган этой общественно-научной организации, видевший Иркутск исключительно университетским городом - на своем заседании 3 октября большинством голосов распорядительный комитет признал «желательным устройство в Иркутске высшего учебного заведения общего типа» - не решился навязать свою точку зрения другим ее членам [12, с. 12]. А потому поручил правителю дел подготовить к общему собранию доклад, рисующий возможно более полную историю идеи высшей школы в городе - не случайно тот был назван «Высшее учебное заведение в Иркутске», после прочтения которого, уже в возможно более полном составе, намереваясь обсудить вопрос о желательном типе учебного заведения для города.

Позиция Распорядительного комитета заслуживает, впрочем, более пристального внимания. Она была доведена до сведения общего собрания открывшим его работу председателем комитета Николаем Николаевичем Кармазинским (ок. 1876 - ?). Как исполнительный орган научной организации, каковой является ВСОИРГО, комитет, по его словам, «не счел возможным заниматься вопросом об институте [сельскохозяйственном], выдвинув сразу же вопрос общий, о назревшей в Восточной Сибири нужде в рассаднике чистой науки, каковым в России является университет. Признав такое положение за непререкаемую истину, комитет остановился лишь на типе высшей школы, наиболее отвечающем нуждам и потребностям страны. Таким типом, по мнению большинства комитета, является бельгийская высшая школа» [11].

В приведенном пассаже нетрудно заметить очевидное противоречие. Будь то в бельгийских, или же германских, британских, итальянских, американских и прочих «смешанных» университетах, традиционные факультеты не просто соседствовали с инженерно-техническими, аграрными или «прикладными», но уступали им количественно и по числу обучаемых студентов [8, с. 97]. Впрочем, отсылку к опыту «Запада» в деле университетского строительства следует счесть у Н.Н. Кармазинского не более чем фигуурой речи. Отвечая на вопрос Моисея Аароновича Кроля (1862-1942) о причинах, побудивших отдел вновь поставить на повестку дня «универ- 
ситетский вопрос», он был вынужден со всей откровенностью признать: «воспользовавшись предлогом в виде вопроса о сел[ьско]-хоз[яйственном] институте, комитет поднял общий вопрос об университете с целью пропагандирования в об[щест]ве идеи о нем. Слишком велика нужда в научном рассаднике и культурных людях, чтобы можно было забыть вопрос об университете и согласиться на высшее заведение узкого типа» [11]. На что последовало справедливое замечание гласного Иркутской городской думы, попечителя ряда учебных заведений города, Григория Ивановича Русанова (1861-1922) о том, что «всякое высшее учебное заведение несет с собой культуру. Разговоры об университете теперь бесплодны. Сибирь нуждается и может жить лишь практическими знаниями» [11].

Публикуя свой доклад в составе 44 тома «Известий ВСОИРГО», увидевшего свет только в 1915 г., Ф.Г. Ширяев, желая, по всей видимости, внести определенность в фрормулировки ряда положений своего доклада, подчеркнув, при этом, проуниверситетскую позицию последнего в целом, счел необходимым озаглавить его текст «Университет в Иркутске». Это сделало его работу «настольной книгой» для нескольких поколений местных историков образования, невзирая на то, что автор фактически отправил «университетский вопрос» в указанном выше смысле в архив науки. Он не только снабдил ее весьма красноречивым подзаголовком «историческая справка», но и сопроводил примечанием, в котором признал, что возможность говорить (в докладе) «только о желательности и справедливости открытия в Иркутске именно университета» стала результатом «ознакомления с прессой минувшего века». Начавшийся XX в. и современники, заключает Ф.Г. Ширяев, поставили и предпочли решить вопрос о высшем учебном заведении в Иркутске иначе [14, с. 239].

В свете планов нового университетского строительства, разрабатывавшихся во время Первой мировой войны при новом министре народного просвещения Игнатьеве, Ф.Г. Ширяев вполне мог счесть двусмысленными положения доклада, где полагал не противоречащим университетской идее соседство «чистой» и «прикладной» науки, видел второй сибирский университет единством «научной» и «прикладной» школ [14, с. 264, 266]. Он, впрочем, сопровождал становление подобного университета «смешанного» типа оговорками, связанными с «приспособлением к местным условиям». К числу каковых относил появление на первых порах прикладных курсов для вольнослушателей, а также возможность зачисления в число слушателей фризико-математического факультета выпускников сибирских реальных и коммерческих училищ.

«Оппоненты» классического, или высшего учебного заведения «общего типа», участвовавшие в собрании общественности города под эгидой ВСОИРГО, не преминули, однако, воспользоваться прозвучавшим в заглавном докладе «реверансом» в сторону новых, на их взгляд, тенденций в организации высшей школы в России. И на голосование 
(«баллотировку записками») по вопросу о желательном для Иркутска типе высшего учебного заведения было вынесено не два возможных ответа - «университет» и «специальный институт», как на то рассчитывали организаторы, а три: «университет», «университет смешанного типа» (он, к слову, фигурировал в отчетах также как «университет в предложенном докладом виде») и «политехникум». Что сделало высшее учебное заведение «общего типа» явным аутсайдером, набравшим только 6 голосов, тогда как за альтернативные формы высшей школы было отдано 15 (пять и десять — соответственно) ${ }^{1}$ [12, с. 115; 11; 4].

Результаты голосования позволили группе участников общего собрания ВСОИРГО опротестовать один из пунктов его постановления, который поручал Распорядительному комитету независимо от решения вопроса о желательном типе высшего учебного заведения для Иркутска, возбудить ходатайство перед покровителем Отдела Иркутским генерал-губернатором Л.М. Князевым об открытии в городе университета [12, с. 13, 115]. Несомненно, именно консерватизм членов Распорядительного комитета породил у участников собрания предложение вынести вопрос о формах высшего учебного заведения на обсуждение и окончательное решение представителями «возможно больших общественных групп» [4]. На Распорядительный комитет общества была возложена, соответственно, обязанность «созвать соединенную комиссию из представителей просветительных обществ, биржевого комитета и представителей города», направив для участия в ее работе представителей отдела [12, с. 13, 115].

О решении последних мы осведомлены опять-таки благодаря Ф.Г. Ширяеву, снабдившему информацию о сделанном им докладе обширным комментарием на страницах «Отчета ВСОИРГО за 1912 год», однозначно свидетельствовавшим о том, что общественное мнение склонилось к идее создания народнохозяйственного института, удовлетворяющего практическим запросам общественного развития. «Соединенное совещание представителей города, биржевого комитета, просветительных учреждений и членов Распорядительного комитета по вопросу о том, какого типа высшее учебное заведение наиболее желательно для Иркутска, большинством голосов высказалось за открытие в Иркутске политехникума с экономическим и сельскохозяйственным отделениями» [12, с. 13].

Газета «Сибирь», не ограничиваясь публикацией информации о результатах голосования, попыталась с доступной для газетных страниц подробностью познакомить читателей с участниками и ходом состоявшегося 7 ноября 1912 г. обсуждения. У сторонников «политехникума» уже не оказалось, по результатам голосования, столь очевидного преимущества перед приверженцами высшей школы «общего типа» (университета) как

${ }^{1}$ Поскольку результаты голосования, воспроизводимые на страницах местных газет, несколько отличаются, мы в качестве более точной версии используем данные, опубликованные на страницах «Отчета ВСОИРГО за 1912 год» Ф.Г. Ширяевым. 
это было десятью днями ранее. И причина коренилась не в одном лишь ограниченном круге участников обсуждения и голосования - 15 человек, девять из которых высказались за политехникум, а шесть - за университет, или наличия уже лишь двух вариантов ответов. Сказалось активное участие в обсуждении (и, соответственно, голосовании) тех делегатов общественности города, кого газета определила как «представители учебной администрации» (главный инспектор училищ, директор мужской гимназии, директор народных училищ и т.д.), то есть чиновников от образования, выражавших интересы достаточно узкой категории учащихся.

Чашу весов в пользу политехникума довелось склонить, безусловно, председателю Иркутского биржевого комитета Альфонсу (Альфонс-Феодор-Фридрих) Васильевичу (Вильгельм) Витте (1863-?), выступлению которого довелось открыть заседание. Вне всякого сомнения, присутствующие на заседании были ознакомлены с результатами обсуждения вопроса о типе «рассадника высшего знания» для Иркутска на заседаниях биржевого комитета от 4 и 15 сентября (т.е. состоявшихся еще до того, как к нему подключились другие общественные организации) и воплотившиеся в заявление от 13 октября, адресованное городскому голове Иркутска [7].

В обращении Иркутского биржевого комитета в частности говорилось: «...так как правительство с одной стороны в принципе решило открыть в Сибири высшее сельскохозяйственное учебное заведение, а с другой стороны потребности торговли и промышленности Восточной Сибири и Дальнего Востока требуют распространения в местном торгово-промышленном классе высших коммерческих и экономических знаний, без каковых знаний не могут обойтись и многие органы управления и самоуправления, то Биржевой Комитет пришел к заключению, что г. Иркутску своевременно возбудить ходатайство об учреждении здесь политехникума с отделениями агрономическим и экономическим» [6, с. 537]. На заседании выступление А.В. Витте завершалось призывом ко всем местным учреждениям и обществам, поддерживая инициативу комитета добиваться данного типа учебного заведения для города, «выступать единодушно».

Принимавший самое активное участие в проходивших 27 октября и 7 ноября обсуждениях Виктор Евграфович Писарев (1882-1972) в будущем известный советский биолог-селекционер и генетик - также каждый раз настойчиво призывал участников, но не к единодушию, а всего лишь к тому, чтобы называть предмет обсуждения и голосования «настоящим его именем». Будучи выпускником Казанского университета и специального Московского сельскохозяйственного ${ }^{1}$ института и видевший проблему с двух противоположных сторон, он настаивал на недопустимости отождествления университетского образования с тем типом высшей школы, который предпочитал называть «университетом в русском смысле» [4]. Последний выступал синонимом исчерпанности

\footnotetext{
${ }^{1}$ Бывшая Петровская сельскохозяйственная академия.
} 
прежней формы - четырехфакультетного «классического» университета, нацеленного на подготовку государственной бюрократии - eе несоответствия стремительно меняющейся реальности и все также дистанцирующейся от требований профессиональной подготовки.

Ярким критиком доживающего свой затянувшийся век «университета в русском смысле» и пропагандистом трех новых типов высшей школы «университетского характера» - политехникума, коммерческого и сельскохозяйственного института ${ }^{1}$ - в рассматриваемые годы стал Владимир Иванович Вернадский (1863-1945). Однако, даже со всей определенностью констатировав факт того, что «русская высшая школа страдает от недостаточного сознания жизненной необходимости для нее больших типов новой высшей школы» [3, с. 281], ученый не рискнул вырваться из колеи традиционных представлений. Складывавшейся в России «системе высшего образования, центром которой не являются университеты», он предпочел возврат к исчерпавшему себя традиционному укладу университетской жизни, не способному к прорыву в будущее, но дающему «в среднем гораздо более широкую основу для организации высшего образования, чем уклад политехнических, коммерческих, сельскохозяйственных школ. Во всяком случае, он испробован жизнью и представляет нечто известное» [2, с. 308, 310].

Финал «иркутской» истории с выбором желательного для города типа высшего учебного заведения оказался столь же тривиальным. Заключительное уже не столько обсуждение, сколько рабочее совещание было проведено в городской управе, где участники были ознакомлены с содержанием доклада Комиссии по вопросу об устройстве в городе Иркутске сельскохозяйственного института, созданной по инициативе Иркутского городского управления. И хотя ее председатель² Аркадий Викторович Вознесенский (1864-1936) - директор Иркутской магнитно-метеорологической обсерватории и гласный Иркутской городской думы - склонялся в ходе предыдущих обсуждений в пользу открытия в городе политехникума, подготовленный доклад [5] не вышел за узкие рамки задачи обоснования целесообразности размещения в городе узкоспециального сельскохозяйственного учебного заведения. По результатам работы совещания, большинством голосов поддержавшего основные идеи и положения доклада, в адрес Иркутского генерал-губернатора было на-

${ }^{1}$ В своей статье «1911 год в истории русской умственной культуры», опубликованной в Ежегоднике газеты «Речь» за 1912 г., он писал: «Работу министерства народного просвещения делают другие ведомства; так сейчас крупная роль в истории русской культуры связана с деятельностью главного управления земледелием и землеустройством не только в организации почвенных исследований, разнообразных сельскохозяйственных станций, но и в создании новых, небывалых в России кафедр, новых начинаний, тесно связанных с ростом научного мышления» [1, с. 268].

2 Членами Комиссии являлись А.С. Первунинский, П.В. Зицерман, В. Кокоулин и И.И. Серебренников. 
правлено ходатайство о возбуждении в надлежащем порядке вопроса об открытии в городе высшего учебного заведения с «агрономическим и другими близкими сельскому хозяйству отделениями».

\section{Список использованной литературы и источников}

1. Вернадский В. И. 1911 год в истории русской умственной культуры / В. И. Вернадский // Избранные труды; [сост., автор вступит. ст. и коммент. Г. П. Аксенов]. М. : Российская политическая энциклопедия (РОССПЭН), 2010. - С. 250-269.

2. Вернадский В. И. Высшая школа в России / В. И. Вернадский // Избранные труды... С. 305-323.

3. Вернадский В. И. Задачи высшего образования нашего времени / В. И. Вернадский // Избранные труды... С. 270-282.

4. Высшее учебное заведение в Иркутске // Молодая Сибирь. - 1912. - 30 окт.

5. Доклад Комиссии по вопросу об устройстве в городе Иркутске сельскохозяйственного института // Известия Иркутской городской думы. - 1912. - Т. 3, № 23-24. - С. 1-16.

6. Заявление Иркутского биржевого комитета от 13 октября 1912 г. № 221 об открытии в Иркутске высшего учебного заведения // Известия Иркутской городской думы. - 1912. - Т. 3, № 17-18. - С. 537-544.

7. И. А. Совещание по вопросу об открытии в Иркутске высшего учебного заведения / И. А. // Молодая Сибирь. - 1912. - 9 нояб.

8. Иванов А. Е. Высшая школа России в конце XIX - начале XX века / А. Е. Иванов. - М. : Б. и., 1991. - 392 с.

9. Майдачевский Д. Я. «Большая и грустная ошибка»: газета «Деловая Сибирь» и полемика по «университетскому» вопросу, 1916-1917 гг. / Д. Я. Майдачевский // Иркутский историко-экономический ежегодник: 2017. - Иркутск : Изд-во БГУ, 2017. - С. 33-39.

10. О высшей школе в г. Иркутске // Сибирь. - 1912. - 9 нояб.

11. О высшей школе в Иркутске // Сибирь. - 1912. - 30 окт.

12. Отчет Восточно-Сибирского отдела Императорского русского географического общества за 1912 год / сост. Ф. Г. Ширяев. - [Б.м.] : И.П. Казанцев, 1914. - 117 c.

13. Очерки истории Иркутского государственного университета: учеб. пособие / И. В. Олейников, С. И. Кузнецов, Ю. А. Петрушин, Ю. А. Зуляр ; под ред. Ю. А. Зуляра. - Иркутск : Изд-во ИГУ, 2012. - 144 с.

14. Ширяев Ф. Университет в Иркутске. (Историческая справка) / Ф. Ширяев // Известия Восточно-Сибирского отдела Русского географического общества. - Иркутск, 1915. - Т. 44. - С. 239-266.

\section{Информация об авторе}

Майдачевский Дмитрий Ярославович — кандидат экономических наук, доцент, кафедра истории и международных отношений, Байкальский государственный университет, Россия, 664003, г. Иркутск, ул. Ленина, 11; e-mail: maid1960@mail.ru

\section{Author}

Dmitry Ya. Maidachevsky - PhD in Economics, Associate Professor, Department of the History and International Relations, Baikal State University, 11 Lenin St., Irkutsk, 664003, Russia; e-mail: maid1960@mail.ru 